\title{
Pre-hospital environment bleeding: from history to future prospegts
}

\author{
Bruno M. Pereiraa ${ }^{1,2,3,4}$, Alcir E. Dorigatti2 ${ }^{2}$ Luis Guilherme M.B. Calderon ${ }^{3}$, Mayara Negrão4, \\ Guilherme Meirelles ${ }^{5}$ Juan C. Duchesne ${ }^{6}$
}

${ }^{1}$ Post Graduation and Research Division, Masters Program in Health Applied Sciences, Vassouras University,

Vassouras, RJ, Brazil

${ }^{2}$ Grupo Surgical, Campinas, SP, Brazil

${ }^{3}$ Terzius Institute of Education, Campinas, SP, Brazil

${ }^{4}$ Campinas Holy House, Campinas, SP, Brazil

${ }^{5}$ Division of Trauma Surgery, Department of Surgery, UNICAMP, Campinas, SP, Brazil

${ }^{6}$ Department of Surgery Tulane, Norman McSwain Level I Trauma Center, New Orleans, Louisiana, USA

\begin{abstract}
While the blood was related to life since antiquity, scientific investigations on anatomy and physiology of the circulation system had to wait until the arrival of the $16^{\text {th }}$ century. In trauma patients, hemorrhagic shock is the main risk factor for multiple organ dysfunction and consequent increased mortality. On the pre-hospital setting intravenous administration of crystalloid solution became the more common intervention during resuscitation of trauma patient due to many reasons although currently new discussions have blossomed on regards type of fluids and resuscitation. The object of this manuscript is to review the history of pre-hospital care bleeding management and to gather new perspectives for the future. Herein authors discuss several issues on bleeding control: 1. Current status and future possibilities on stop the bleeding in the the pre-hospital setting - movements after the Hartford Consensus, use of topic homeostatic agents, tourniquets, REBOA and other radical interventions; 2. Damage control resuscitation in the pre-hospital environment - is massive transfusion protocol feasible at this setting? Tranexemic acid should be done? Possibilities that may improve survival and coagulopathy understanding; 3 . Critical decision and decision making on stop the bleed; 4. Proposed flowchart on bleeding control.

The implementation of measures to stop acute bleeding in the pre-hospital setting is a well-known and well-founded measure. However, the provision of current evidence demonstrates that these measures go far beyond compression and elevation of the limb as was known in the past. The deep understanding of the mechanism of coagulopathy and the new adjuvant arsenal to control bleeding are essential for a better quality of pre-hospital medical care as well as lower mortality rates.
\end{abstract}

Key words: bleeding, pre-hospital care, trauma, resuscitation.
Anaesthesiol IntensiveTher 2019;51, 2:240-248

Received: 16.04.2019, accepted: 20.05.2019

\section{CORRESPONDING AUTHOR:}

Bruno M. Pereira, MD, MSc, PhD, University of Vassouras, Brazil, e-mail: dr.bruno@gruposurgical.com.br
While the blood has been related to life since antiquity [1], scientific investigations on anatomy and physiology of the circulation system had to wait until the arrival of the $16^{\text {th }}$ century.

Soon after the end of the $18^{\text {th }}$ century, specifically in 1819, James Blundell, an English obstetrician, saved many patients with postpartum hemorrhage, describing for the first time the benefits of blood transfusions. "Patients received in three hours only $236 \mathrm{~mL}$ (8 oz) of blood, but they said that life was infused in their body" [2]. For many years, the lack of knowledge about the human antigenic blood constitution and the severe reactions of incompatibility were an impediment to blood transfusion. It became widely used one century later with the discovery about blood types and cross-reactive techniques $[3,4]$.

In trauma patients, hemorrhagic shock is the main risk factor for multiple organ dysfunction and consequent increased mortality [5]. In the pre-hospital setting intravenous administration of crystalloid solution became the more common intervention during resuscitation of trauma patients due to many reasons although currently new dis- 
cussions have blossomed as regards type of fluids and resuscitation. Indeed, fluid replacement is now taken with caution, with different comprehension from what it was at the time of World Wars I \& II, and the Wars of Korea and Vietnam. The updated understanding on fluid replacement led the IFA (International Fluid Academy) to suggest the rule of 4Ds for fluids: Drugs, Dose, Duration, De-escalation [6]. In the current concept, it is paramount to give the right fluid, at the right moment considering each patient population, risk factors and ongoing morbidity. It is also important to consider volume and fluid infusion rates based on pharmacokinetics, pharmacodynamics and toxicity. To date, the continuous infusion of fluids after the resuscitation phase may also be considered with caution. When the expected resuscitation target is reached, fluid infusion should be discontinued [6].

Crystalloids are electrolyte-enriched solutions and sodium is the main electrolyte contained in these solutions. This chemical element diffuses rapidly with water through the vascular endothelium and stays free in the extravascular and interstitial compartment. By the infusion of one liter of crystalloids, $75 \%$ of this volume spreads into the interstitial space; therefore only $25 \%$ maintains plasma volume expansion [7]. Due to its availability and relative safety, crystalloid solutions became the fluid of choice in the treatment of hemorrhagic shock during the $19^{\text {th }}$ and early $20^{\text {th }}$ centuries [8-10].

Over an historic perspective, during World War I resuscitation with crystalloids seemed not to be effective [11]. Plasma was then found to be a more effective volume expansion solution together with whole blood transfusion, which became the first option during that period of conflict [12]. During WW II, the goal was to keep systolic blood pressure higher than $85 \mathrm{~mm} \mathrm{Hg}$ until the bleeding source was taken under control [13-15].

During the Vietnam War, crystalloid solutions returned to the scene as the field resuscitation first choice, based on studies indicating that resuscitation with Lactated Ringer was the best option when compared to whole blood when looking specifically for improvement of survival [16-20]. Later on, research demonstrated that an increasing crystalloid volume infusion was correlated with intestinal perfusion decrease, abdominal compartment syndrome, pulmonary and cardiac dysfunction and death [21-23].

In the same period new techniques of blood fractionation were developed dividing whole blood into units of red blood cells, plasma and platelets. In addition, even without a single study showing the effects of using fractionated blood in patients with hemorrhagic shock, this was the way of tak- ing all indicated transfusions including outside the war field [24, 26]. Medical practice was becoming far away from whole blood transfusion by that period of time. This continued in the last three decades of the $20^{\text {th }}$ century, when studies indicated that the use of Lactated Ringer and up to six unit of red blood cells could be used without causing coagulopathy. Other studies indeed pointed out that there was no indication for transfusion with plasma or platelets without laboratory coagulation [27, 28].

Carrico et al. in an important study affirmed that the use of two liters of crystalloids while waiting for blood transfusion was safe. This study was widely disseminated around the world by the American College of Surgeons through the Advanced Trauma Life Support program, encouraging thousands of doctors to perform an aggressive volume resuscitation for many years. Multicenter studies have never shown the benefit of using aggressive volume resuscitation whatsoever [30, 31]. In 1994 another study showed that the infusion of a major volume of fluid infusion before bleeding control was associated with worse prognosis [32]. Recent studies have indicated that when a patient sustains extensive tissue damage associated with severe hypotension, coagulation dysfunction rapidly occurs [33]. Several hypotheses justify this phenomenon, for instance: 1) aggressive fluid administration - to be responsible for whole blood and coagulation factors' dilution and fibrinolysis, 2) release of plasminogen activating factor secondary to tissue injury $[34,35]$. Other factors would be hypothermia and acidosis, affecting the coagulation cascade and the consumption of coagulation factors by itself [33].

Coagulopathy was first observed in patients with severe traumatic injuries independent of the resuscitation process with a six-fold mortality rate increase [36-39]. Researchers found an endothelial membrane, later defined as the glycocalyx, noted to have an important role in endothelial permeability maintenance and suggested that during transfusion of plasma in the hemorrhagic shock population, glycocalyx preservation is greater than when compared with resuscitation with other fluids [40]. In severely traumatized individuals, coagulopathy has a multifactorial mechanism. However, it is now understood that innumerable molecules and cellular mediators integrate this complex mechanism from the moment of trauma, even before the volume loss is observed [41]. Due to this evidence, military surgeons started again to use the concept of whole blood used in past wars but now gathering packed red blood cells (PRBC), fresh frozen plasma (FFP) and platelets (PLT) into their transfusion protocols. Results from this experience in the wars of Iraq and Afghanistan showed that patients receiving 
a high ratio of FFP related to the number of PRBCs had a lower mortality rate when compared to those protocols that used less FFP [42]. The result of this study was widely reproduced in the civilian field, for blunt and penetrating trauma mechanisms in a ratio of $1: 1: 1$ [42-47].

The promising results of the use of a balanced resuscitation with plasma have been attributed to the reduction of inflammation, edema and vascular permeability by repairing the tight junctions of the vascular endothelium and the glycocalyx layer, besides preserving the platelet function and clot formation [48-50]. The use of plasma also reduces blood hypercoagulability by modulating the generation of thrombin [51].

A limiting factor in the use of FFP is the preparation time: 45 minutes before starting the transfusion. In 2009, a study that evaluated the transfusion time of each blood component found a bias in retrospective studies that supported the use of balanced resuscitation. The time of the first transfusion of FFP was significantly longer than PRBC, 93 minutes versus 18 minutes respectively, so patients did not survive until transfused with plasma, generating therefore a survival bias [52].

A prospective study done to overcome this impasse showed that although the use of plasma resuscitation did not improve survival within 24 hours, there were fewer deaths due to exsanguination in this group of patients and up to three hours mortality decrease. There was no difference in complications between the groups with balanced resuscitation with plasma when compared to those with use of PRBC alone [53-56]. New studies discuss the benefit of early plasma use in the prehospital setting, pointing to a 30-day mortality reduction in those patients with a high risk of severe hemorrhagic shock who received plasma in aeromedical transport before hospital admission [57]. However, another study evaluating the use of plasma in ground transport did not show mortality rate reduction for short transports [58].

The use of whole blood as an option for transfusion of severely traumatized patients came back in the conflicts of the Middle East, a practice

TABLE 1. Essential differences between transfusion with whole blood and 1:1:1 ratio

\begin{tabular}{|l|c|c|} 
& $500 \mathrm{ml}$ whole blood & $\begin{array}{c}660 \mathrm{~mL} \\
\text { (1 FFP : 1 PRBC: 1 PLT) }\end{array}$ \\
\hline Hematocrit & $\uparrow 38 \%$ to $50 \%$ & $\uparrow 29 \%$ \\
\hline Platelets (UI/mL) & $\begin{array}{c}150.000 \text { to } 400.000 \\
\text { full activity }\end{array}$ & 88.000 \\
\hline Coagulation factors & $100 \%$ activity & $65 \%$ activity \\
\hline Others & - & Presence of anticoagulants \\
\hline
\end{tabular}

abandoned since the 1970s [59,60]. Patients who received whole blood, compared to those who received a balanced volume resuscitation with plasma, achieved greater survival in 24 hours and 30 days [61-64]. Some differences between whole blood and balanced resuscitation with plasma are shown in Table $1[65,66]$.

As a result of changes in the scientific evidence regarding resuscitation of the traumatized patient, a restriction was made on the use of crystalloid fluids. In animal models, mean systolic blood pressure values of $94 \mathrm{~mm} \mathrm{Hg}$ and mean arterial pressure of $64 \mathrm{~mm} \mathrm{Hg}$ were those reported as limits for maintenance of hemostasis [67-70]. This concept was known as permissive hypotension or hypotensive resuscitation.

Ironically, there was a pendulum movement in the history of trauma patients' resuscitation management. However, it is necessary to emphasize that current management is based on solid evidence with greater understanding of the involved pathophysiological mechanisms. Also, development of new technologies in the diagnosis of coagulopathy, such as thromboelastography (TEG) for instance, have to date an important role in the management of severe bleeding and coagulopathy, helping healthcare providers in the decision-making process.

TEG was developed 70 years ago to evaluate thrombus initiation, formation, strength, stability and consumption in hyper/hypo coagulation patients [71-74]. Through TEG it is possible to visualize the whole coagulation cascade in real time instead of just the plasma, allowing accurate diagnosis of coagulation factor deficiency or its dilution, hyperfibrinolysis and platelet dysfunction [71, 72].

\section{BLEEDING CONTROL IN THE PRE-HOSPITAL SETTING - CURRENT STATUS AND FUTURE POSSIBILITIES}

Bleeding following severe trauma remains the potentially most preventable cause of death that typically occurs within the first three hours after injury. To improve outcomes we should consider a "care set" that includes measures to facilitate early diagnosis, rapid bleeding control, local and systemic hemostatic support, and reduction of the time spent at the scene [75]. In the last decade a paradigm shift has been witnessed regarding treatment strategies and transfusion algorithms [76], with emphasis on hemostatic resuscitation and damage control. The key objective of this proactive and empirical approach to transfusion is to focus directly on acute coagulopathy subsequent to traumatic injury, which in turn is associated with a fourfold increase in mortality and unfavorable patient outcomes. 
Identification of the bleeding source should be performed as part of the initial evaluation at the scene. Good clinical insight and a high suspicion rate remain important diagnostic tools. Points of care coagulation measurements, for instance, are of limited value in patients with significant bleeding. In the same way, prehospital use of ultrasonography, for diagnostic purposes only, remains in discussion. Critics argue that it adds little additional information and may delay the transfer to the hospital for definitive control of bleeding.

Undoubtedly the immediate priority is to locate any external bleeding sites and provide direct control. The recently published Hartford Consensus, Chapters I-IV, of the American College of Surgeons also suggests new evidence-based methods to stop the bleeding [77]. Foley catheters inserted in the path of the penetrating wound, for example, inflated and subsequently retracted to the edge of the skin, are good adjuncts for junctional injuries and neck wounds. Topical hemostatic dressings help in clot formation and can be applied to cavities where bleeding is difficult to directly control.

The use of topic hemostatic agents is an old concept, used in different ways by ancient civilizations. The Egyptians made use of a mixture of wax, grease, and barley in an effort to stop the bleeding. In ancient Greece, priests and healers of the time used hemostatic herbs on traumatic wounds. Recently, advances in biotechnology have resulted in the development of topical hemostatic agents that are currently available for pre-hospital use. Such agents range from absorbable topical hemostats, such as gelatins, collagen and regenerated oxidized cellulose to biologically active topical hemostats such as thrombin, biological sealants or other agents combined.

The use of tourniquets in limbs is now well established in pre-hospital care and has already been shown as a life-saving measure, particularly when applied before the onset of hemorrhagic shock. Complications such as nerve damage are rare when tourniquets are properly applied. The Eastern Association for the Surgery of Trauma recently published guidelines recommending its use in the civilian setting as a measure of interruption of severe bleeding in cases of penetrating lower limb injuries [78].

Radical interventions to control life-threatening bleeding include pre-hospital thoracotomy for aortic cross-clamping and the use of the Resuscitative Endovascular Balloon for the Occlusion of the Aorta (REBOA) for larger bleeding of the trunk and pelvis. Pre-hospital thoracotomy for penetrating trauma is an established intervention in a physician-led emergency system and is associated with $18 \%$ survival rates in selected patient groups. However, all efforts should be focused on rapid transit to the hospital in order to obtain definitive surgical treatment. Relief of tamponade with cardiac injury control is still the primary goal for pre-hospital thoracotomy. REBOA has been used successfully in emergency rooms with or without fluoroscopy support, in any retroperitoneal zones (I, II or III). REBOA has already been used in the war field and has become promising for use in the pre-hospital environment [77-80]. Indeed, REBOA may play an important role in the prehospital management of severe pelvic injuries, with the balloon at the level of the aortic bifurcation, aiding in the control of catastrophic pelvic bleeding $[79,80]$. Globally, both REBOA and transfusion of blood products in an out-of-hospital environment are not yet usual.

Direct control of bleeding should be accompanied by hemostatic resuscitation and damage control surgery when indicated. The efficacy of therapy with high doses of blood components and the ideal plasma ratio is divergent. The PROPPR study was the first randomized controlled clinical trial that proposed investigating ratios of blood products in trauma [81].

Hemostasis is dependent on fibrinogen as a substrate for clot formation. Fibrinogen levels decrease rapidly and significantly during massive bleeding, a fact associated with increased mortality, and its early supplementation (cryoprecipitate) has been shown to improve patient survival [82]. Early and high dose fibrinogen replacement is the subject of three randomized trials in the United Kingdom (CRYOSTAT - ED and E-FIT 1) and Austria (FiTIC pre-hospital). The fibrinogen concentrate has the potential to be the main pro-coagulant agent for pre-hospital hemostatic resuscitation. E-FIT 1 specifically demonstrates that the early use of fibrinogen is feasible in trauma, but larger randomized clinical trials are needed to determine its results in reducing mortality [83]. All patients with severe bleeding have a profound activation of the fibrinolytic system [84]. The CRASH-2 study showed clear benefits of reducing mortality when using early tranexamic acid (TXA) in hemorrhagic shock following trauma. Its use should be considered in all patients with hemorrhagic shock less than 3 hours after the traumatic event [85].

Again, effective treatment of pre-hospital bleeding depends on rapid identification of bleeding, direct control, hemostatic resuscitation, and rapid transfer to a trauma center.

\section{DAMAGE CONTROL RESUSCITATION IN THE PRE-HOSPITAL SETTING}

The high prevalence and impact of coagulopathy in trauma victims requires a strategy of proac- 
tive emergency room action that should include administration of PRBC, FFP, platelets and tranexamic acid [86]. Damage control resuscitation (DCR) provides transfusions with plasma and platelets, as well as PRBC in an immediate and sustained manner, as part of the massive transfusion protocol for patients with severe life-threatening bleeding. Rapid and proactive treatment of trauma-associated coagulopathy is now recognized as essential for reducing mortality. Although the early and effective reversal of coagulopathy is well documented, its prevention in massive transfusion remains under discussion, and randomized controlled trials are still scarce.

\section{MASSIVE TRANSFUSION PROTOCOL}

Patients with severe life-threatening bleeding require massive transfusion protocol (MTP) activation. There are several definitions of massive transfusion ranging from 10 to 20 units of PRBCs in 24 hours, or the use of 50 units of blood components in 24 hours. From a practical point of view, transfusion requirement of $>4 \mathrm{PRBC}$ in 1 hour, or blood loss $>150 \mathrm{~mL} \mathrm{~min}^{-1}$ with hemodynamic instability and $A B C$ score $>1$, is a reasonable indication for MTP. ABC score is shown to have sensitivity of $75 \%$ and specificity of $85 \%$ [86].

\section{RECOMBINANT FACTOR VIIA}

The use of recombinant factor VIla in trauma has complemented the therapeutic armamentarium in the treatment of trauma-associated coagulopathy (ACoTS). Recombinant activated factor VII (rFVIla) is a hemostatic agent originally developed for the treatment of hemophilia, factor VII deficiency, Glanzmann's thrombocytopenia and patients refractory to platelet transfusion. Activation of platelets at the lesion site is the reason for the localized action of rFVIIa, since it causes clotting at the site of bleeding. Controlled and randomized prospective trials with different doses of $\mathrm{rFVII}$ a are required to explore the potential efficacy of lower doses in ACOTS to reduce costs and adverse effects such as thromboembolic complications. The efficacy and safety of rFVIla as adjunctive therapy for the control of patients with severe blunt and penetrating trauma were evaluated in a randomized, doubleblind, placebo-controlled study. The authors compared three doses of rFVIla (doses of 200, 100, and $100 \mathrm{~g} \mathrm{~kg}^{-1}$ ) with three placebo doses in addition to standard treatment for patients who received 6 PRBC units within a 4-h period. In 143 traumatized patients, PRBC transfusion was significantly reduced with rFVIla compared to placebo, and the need for massive transfusion (20 PRBC units) was reduced (14\% vs. $33 \%$, respectively). In penetrating trauma (134 patients), there was no reduction in mortality.
Adverse events, including thromboembolic events (a total of 12, six in each group) were equally distributed between the groups. The authors concluded that rFVIla is safe within the dose investigated and may be a promising adjuvant for existing trauma therapy. The effects of liberal administration of rFVIla in trauma patients with bleeding are unknown because their procoagulant effect must be balanced against a real risk of thromboembolic events [59].

\section{FIBRINOGEN AND CRYOPRECIPITATE}

Fibrinogen deficiency develops earlier than other coagulation factors. Fibrinogen is therefore an obvious target for the replacement of cryoprecipitate containing fibrinogen, factor VIII, factor XIII, and von Willebrand factor or fibrinogen concentrate. Updated guidelines recommend the use of one of the two products if plasma fibrinogen levels fall below $1.0 \mathrm{~g} \mathrm{~L}^{-1}$. Concerns about patient exposure to a large number of donors and the associated risk of viral transmission limit the use of cryoprecipitate to situations where conventional treatment has failed [83].

\section{TRANEXAMIC ACID}

Fibrinolysis is a normal response to surgery and trauma in order to maintain vascular permeability and may become exaggerated (hyperfibrinolysis) in some cases. Tranexamic acid (TXA) is an antifibrinolytic drug, analogous to lysine, and interferes with the binding of fibrin to plasminogen, which is required for the activation of plasmin. Anti-fibrinolytic drugs can prevent breakage of the clot and thereby reduce blood loss in trauma. The results of the CRASH-2 study showed that early treatment with tranexamic acid is more effective in reducing the risk of death from bleeding. Patients who received tranexamic acid within 1 hour of injury had a lower bleeding-related mortality rate $(5.3 \%$ vs. $7.7 \%$ for placebo). Similarly, patients who received treatment within 1-3 hours after injury also had a significantly lower risk of death from bleeding. However, patients who received TXA with more than 3 hours of injury had an increased risk of death compared to placebo, $4.4 \%$ vs. $3.1 \%$, respectively. The current recommendations for the use of TXA are as follows: 1) TXA should be routinely used in patients with trauma, with evidence of bleeding, 2) TXA should be included in the MTP, 3) TXA should be given within 3 hours of injury, 4) administer $1 \mathrm{~g}$ of TXA intravenously, followed by infusion of $1 \mathrm{~g}$ over 8 hours [83-86].

\section{CALCIUM ADMINISTRATION}

Ionized hypocalcemia is common in the critically ill and associated with increased mortality. Calcium is an important cofactor for many components of the coagulation cascade. Citrate, used as an antico- 
agulant in many of the prepared components for transfusion, causes calcium depletion and exacerbates hypocalcemia. The dose-response effect of hypocalcemia on coagulation is difficult to measure. A recent non-systematic review has shown that calcium concentrations less than $0.6-0.7 \mathrm{mmol} \mathrm{L}^{-1}$ could lead to significant coagulation changes and recommended keeping the concentration level of at least $0.9 \mathrm{mmol} \mathrm{L}^{-1}$ [63].

\section{AGED PRBC}

Red cell transfusion with high storage time has been associated with increased rates of infectious complications and multiple organ failure. Although the lifespan of erythrocyte units is about six weeks, the adverse effects of administration (believed to be leukocyte-mediated) have been shown to be frequent after two weeks of storage. When blood is stored, the level of antioxidants decreases, resulting in oxidative damage that converts hemoglobin to methemoglobin, which cannot bind to oxygen. If blood is stored for more than 7 days, it loses 2,3-DPG by shifting the oxygen-hemoglobin dissociation curve to the left, thereby decreasing the amount of oxygen to the tissues. Storage also promotes hemolysis and acidosis. Researchers have shown that transfused blood is an independent predictor of multiple organ failure and death. A large retrospective cohort study of patients with recent trauma showed that transfusion of red cells stored for more than two weeks was associated with a significant increase in the chance of death. This finding was observed despite the leucoreduction, but it was evident only among the patients who received at least six units of packed red blood cells. Recently donated red cells are therefore preferable to trauma victims requiring massive transfusion, although such practice has obvious logistical and resource implications [55, 56, 60, 63].

\section{STOPPING THE BLEEDING IN THE PRE-HOSPITAL} SETTING: DECISION-MAKING AND CRITICAL DECISION

Bleeding is responsible for a large number of trauma deaths in the prehospital setting before and after the arrival of the emergency medical service at the scene. Although it is impossible to correlate the prognosis with exact amounts of blood loss, it has certainly been well demonstrated that as blood loss increases, so does the incidence of death. In order to prevent greater lethality of patients rescued in an austere or pre-hospital setting, it is essential that the rescue team is focused on preventing or fighting the lethal triad consisting of hypotension, acidosis and hypothermia. This set of factors is strongly associated with multiple organ failure and subsequent death when not readily reversed. The need for perception, control, and correction of hemorrhage and the lethal triad is as important as the recognition and obtaining of a safe airway.

All approaches to controlling external hemorrhage have their pros and cons. Each modality has its risks and benefits, advantages and disadvantages when compared to the following, and none of them should be considered as a "gold standard" in the control or bleeding management. Each case may be suitable for use of any particular device, modality or approach. It is very important to stress that ensuring a safe airway and cervical spine protection, effective ventilation and hemorrhage control is the basis of any life-sustaining measure, as well as the prevention of the lethal triad.

Practice of constant training and simulations enhances the life-saving physician's ability to make critical decisions as it exposes one to different scenarios with repetition and debriefing. It is also in these simulation scenarios, with adequate training, that the ability to stagger bleeding interruption measures become clearer. For example, in the failure of wound compression effectiveness as a measure of bleeding discontinuation, limb elevation, proximal artery compression, or tourniquet use should be employed. It is neither prudent nor correct to "wait a little longer" once the non-effectiveness of the hemorrhage control has been established. The medical team should not miss precious seconds trying to decide whether a tourniquet is needed. Digital pressure should be applied directly to the bleeding source and held for 3-5 minutes. Bleeding should stop immediately. Commercial devices that apply pressure to the wound while maintaining direct and uninterrupted compression of the bleeding can be extremely helpful [87]. The application of the tourniquet should be about three centimeters proximal to the wound by adjusting it until the bleeding stops. For most extremity bleeding, this treatment is safe and effective [88]. For wounds on the proximal ends, mutilated extremities, and especially junctional wounds (e.g., groin, armpit, shoulder and neck), tourniquets may not be applicable. CRoC (Combat Ready Clamp) type tourniquet, JETT (Junctional Emergency Tourniquet Tool) or ITClamp (a device for temporary interruption of hemorrhage in places of difficult compression), are rising options [88, 89].

Immobilization is also very useful in the prehospital setting. Immobilization of the extremity helps maintain anatomical position and natural blood flow. In the case of a lacerated radial artery, for instance, direct external compression, maintenance of the natural position of the wrist keeps the flow of the ulnar artery ensuring that the site of the injury is not under more pressure than it normally would be. Immobilization can also help prevent the dislodgment of a formed clot. For pelvic and femoral fractures, bleeding is al- 


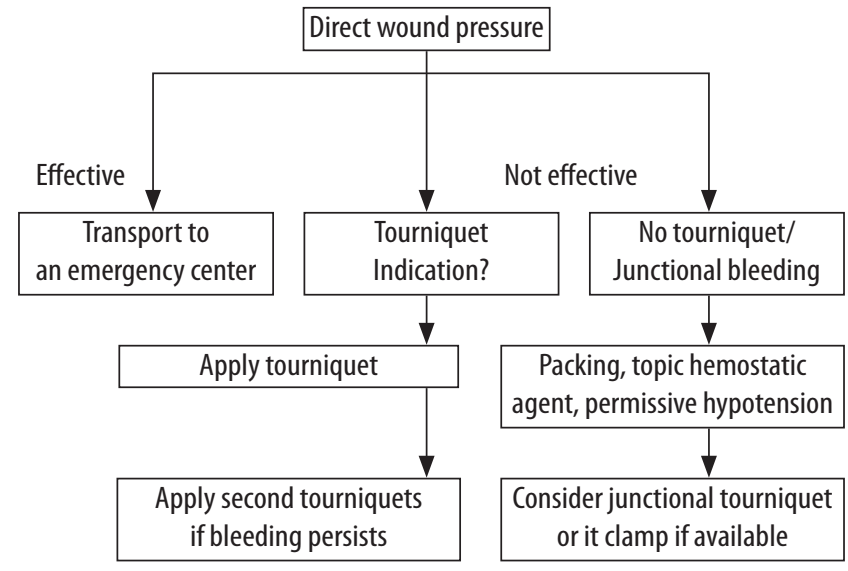

FIGURE 1. Proposed bleeding control flowchart

ways a significant concern. Figure 1 represents a proposed flow chart for hemorrhage control.

\section{OTHER PERSPECTIVES FOR THE FUTURE}

There are some new therapies that are appearing to be of great promise.

Self-expanding polymer foams/sponges are an interesting option. When packaged in a wound, these products are able to absorb 30 times their weight in water, while expanding many times their size [89]. These actions serve two purposes: 1) expansion provides compression and force similar to tamponade at the bleeding site; and 2) by absorbing water from the source of bleeding, they concentrate the blood products naturally used by the body for coagulation. It is promising as a form of hemostasis to control damage to open thoracic organs and abdominal trauma (penetrating wounds) [90].

Another new therapy with perhaps the greatest potential for severe and massive bleeding control is a group of products known as procoagulant supplements [90]. Such dressings are impregnated with highly concentrated human coagulation factors and calcium, surpassing most other hemostatic agents in the immediate cessation of bleeding and in promoting wound coagulation. Containing biologically active compounds derived from coagulation, they are estimated to have an almost 100 -fold increase in cost compared to other current products.

\section{CONCLUSIONS}

The implementation of measures to stop acute bleeding in the pre-hospital setting is a well-known and well-founded measure. However, the current evidence demonstrates that these measures go far beyond compression and elevation of the limb, as was known in the past. A deep understanding of the mechanism of coagulopathy and a new adjuvant arsenal to control bleeding are essential for a better quality of pre-hospital medical care as well as lower mortality rates.

\section{ACKNOWLEDGEMENTS}

1. Source of funding: none.

2. Conflict of interest: none.

\section{REFERENCES}

1. Wood CS. A short history of blood transfusion. Transfusion 1967; 7: 299-300.

2. Blundell J. Some account of a case of obstinate vomiting, in which an attempt was made to prolong life by the injection of blood into the veins. Med Chir Trans 1819; 10 (Pt 2): 296-311. doi: 10.1177/ 09595287190100p204.

3. Schmidt PJ. Transfusion in America in the eighteenth and nineteenth centuries. N Engl J Med 1968; 279: 1319-1320. doi: 10.1056/ NEJM196812122792406

4. Spinella PC. Warm fresh whole blood transfusion for severe hemorrhage: US military and potential civilian applications. Crit Care Med 2008; 36: S340-345. doi: 10.1097/CCM.0b013e31817e2ef9.

5. Kobayashi L, Costantini TW, Coimbra R. Hypovolemic shock. Surg Clin North Am 2012; 92: 1403-1423. doi: 10.1016/j.suc.2012.08.006.

6. Malbrain ML, Van Regenmortel N, Owczuk R. It is time to consider the four D's of fluid resuscitation. Anaesthesiol Intensive Ther 2015; 47: 1-5. doi: 10.5603/AIT.a2015.0070.

7. Marino P. The ICU book. $4^{\text {th }}$ ed. Wolters Kluwer Health, Philadelphia $2014 ; 217-234$.

8. Jennings CE. The intra-venous injection of fluid for severe hæmorrhage. Lancet 1882; 120: 436-437. doi: 10.1016/S0140-6736(02)12554-2.

9. Jennings CE. The intra-venous injection of fluid for severe hæmorrhage. Lancet 1883; 121: 228-229. doi: https://doi.org/10.1016/S01406736(02)38999-2.

10. Pye-Smith RJ. Sheffield public hospital and dispensary: five cases of intravenous injection of saline fluid for hæmorrhage and collapse. Lancet 1892; 139: 913-915. doi: https://doi.org/10.1016/S0140-6736(02)15463-8.

11. Fraser J, Cowell EM. Clinical study of blood pressure in wound conditions. JAMA 1918; 70: 520-535.

12. Hess JR, Thomas MJ. Blood use in war and disaster: lessons from the past century. Transfusion 2003; 43: 1622-1633.

13. Beecher HK. Preparation of battle casualties for surgery. Ann Surg 1945; 121: 769-792. doi: 10.1097/00000658-194506000-00001.

14. Beecher HK. Early care of the seriously wounded man. J Am Med Assoc 1951; 145: 193-200.

15. Beecher HK. Resuscitation, and anesthesia for wounded men, the management of traumatic shock. Charles C. Thomas, Springfield 1949.

16. Shires T, Jackson DE. Postoperative salt tolerance. Arch Surg 1962; 84: 703-706.

17. Fogelman MJ, Wilson BJ. A different concept of volume replacement in traumatic hypovolemia observations on injured man and animal. Am J Surg 1960; 99: 694-701. doi: https://doi.org/10.1016/00029610(60)90016-7

18. Wolfman EF, Neill SA, Heaps DK, et al. Donor blood and isotonic salt solution. Effect on survival after hemorrhagic shock and operation. Arch Surg 1963; 86: 869-873. doi: 10.1001/archsurg.1963.01310110179023.

19. Shires T, Coln D, Carrico J, et al. Fluid therapy in hemorrhagic shock. Arch Surg 1964; 88: 688-693. doi: 10.1001/archsurg.1964. 01310220178027

20. McClelland RN, Shires GT, Baxter CR, et al. Balanced salt solution in the treatment of hemorrhagic shock. JAMA 1967; 199: 830-834. doi: 10.1001/jama.1967.03120110102017.

21. Balogh Z, McKinley BA, Cocanour CS, et al. Supranormal trauma resuscitation causes more cases of abdominal compartment syndrome. Arch Surg 2003; 138: 637-642. doi: 10.1001/archsurg.138.6.637.

22. Brandstrup B, Tønnesen H, Beier-Holgersen R, et al. Effects of intravenous fluid restriction on postoperative complications: comparison of two perioperative fluid regimens: a randomized assessor-blinded multicenter trial. Ann Surg 2003; 238: 641. doi: 10.1097/01.sla.0000094387.50865.23.

23. Cotton BA, Guy JS, Morris JA Jr, et al. The cellular, metabolic, and systemic consequences of aggressive fluid resuscitation strategies. Shock 2006; 26: 115-121. doi: 10.1097/01.shk.0000209564.84822.f2.

24. Westphal RG. Rational alternatives to the use of whole blood. Ann Intern Med 1972; 76: 987-990. doi: 10.7326/0003-4819-76-6-987.

25. Holcomb JB. Fluid resuscitation in modern combat casualty care: lessons learned from Somalia [review]. J Trauma 2003; 54 (5 Suppl): S46-51. doi: 10.1097/01.TA.0000051936.91915.A2. 
26. McSwain NE, Champion HR, Fabian TC, et al. State of the art of fluid resuscitation 2010: prehospital and immediate transition to the hospital. J Trauma 2011; 70: S2-10. doi: 10.1097/TA.0b013e31821b201d.

27. Shackford SR, Virgilio RW, Peters RM. Whole blood versus packed-cell transfusions: a physiologic comparison. Ann Surg 1981; 193: 337-340. doi: 10.1097/00000658-198103000-00015.

28. Counts RB, Haisch C, Simon TL, et al. Hemostasis in massively transfused trauma patients. Ann Surg 1979; 190: 91-99. doi: 10.1097/ 00000658-197907000-00020.

29. Carrico CJ, Canizaro PC, Shires GT. Fluid resuscitation following injury: rationale for the use of balanced salt solutions. Crit Care Med 1976; 4: 46-54.

30. Gattinoni L, Brazzi L, Pelosi P, et al. A trial of goal-oriented hemodynamic therapy in critically ill patients. N Engl J Med 1995; 333 1025-1032. doi: 10.1056/NEJM199510193331601.

31. Velmahos GC, Demetriades D, Shoemaker WC, et al. Endpoints of resuscitation of critically injured patients: normal or supranormal?: a prospective randomized trial. Ann Surg 2000; 232: 409-418.

32. Bickell WH, Wall MJ, Pepe PE, et al. Immediate versus delayed fluid resuscitation for hypotensive patients with penetrating torso injuries. N Engl J Med 1994; 331: 1105-1109. doi: 10.1056/NEJM1994102733 11701 .

33. Brohl K, Cohen MJ, Davenport RA. Acute coagulopathy of trauma: mechanism, identification and effect. Curr Opin Crit Care 2007; 13 680-685. doi: 10.1097/MCC.0b013e3282fle78f.

34. Bickell WH, Wall MJ, Pepe PE, et al. Immediate versus delayed fluid resuscitation for hypotensive patients with penetrating torso injuries. N Engl J Med 1994; 331: 1105-1109. doi: 10.1056/NEJM1994 10273311701

35. Hampton DA, Fabricant LJ, Differding J, et al. Pre-hospital intravenous fluid is associated with increased survival in trauma patients. J Trauma Acute Care Surg 2013; 75: 9-15. doi: 10.1097/TA.0b013e31 $8290 \mathrm{~cd} 52$.

36. MacLeod JB, Lynn M, McKenney MG, et al. Early coagulopathy predicts mortality in trauma. J Trauma 2003; 55: 39-44. doi: 10.1097/01. TA.0000075338.21177.EF.

37. Brohi K, Singh J, Heron M, et al. Acute traumatic coagulopathy. J Trauma 2003; 54: 1127-1130. doi: 10.1097/01.TA.0000069184.82147.06.

38. Gunter OL Jr, Au BK, Isbell JM, et al. Optimizing outcomes in damage control resuscitation: identifying blood product ratios associate with improved survival. J Trauma 2008; 65: 527-534. doi: 10.1097/ TA.0b013e3181826ddf

39. Pidcoke HF, Aden JK, Mora AG, et al. Ten-year analysis of transfusion in Operation Iraqi Freedom and Operation Enduring Freedom increased plasma and platelet use correlates with improved survival. J Trauma Acute Care Surg 2012; 73: S445-452. doi: 10.1097/ TA.0b013e3182754796.

40. Myburgh JA, Mythen MG. Resuscitation fluids. N Engl J Med 2013; 369: 1243-1251. doi: 10.1056/NEJMra1208627.

41. Dutton RP. Management of traumatic haemorrhage - the US perspective. Ansethesia 2015; 70: 108-113. doi: 10.1111/anae.12894.

42. Borgman MA, Spinella PC, Perkins JG, et al. The ratio of blood products transfused affects mortality in patients receiving massive transfusions at a combat support hospital. J Trauma 2007; 63: 805-813. doi: 10.1097/TA.0b013e3181271ba3.

43. Duchesne JC, Hunt JP, Wahl G, et al. Review of current blood transfusions strategies in a mature level I trauma center: were we wrong for the last 60 years. J Trauma 2008; 65: 272-276 [discussion: 276-278] doi: 10.1097/TA.0b013e31817e5166.

44. Teixeira PG, Inaba K, Shulman I, et al. Impact of plasma transfusion in massively transfused trauma patients. J Trauma 2009; 66: 693-697. doi: 10.1097/TA.0b013e31817e5c77.

45. Brown LM, Aro SO, Cohen MJ, et al. A high fresh frozen plasma: packed red blood cell transfusion ratio decreases mortality in all massively transfused trauma patients regardless of admission international normalized ratio. J Trauma 2011; 71 (2 Suppl 3): S358-363. doi: 10.1097/TA.0b013e318227f152.

46. Sperry JL, Ochoa JB, Gunn SR, et al. Inflammation the Host Response to Injury Investigators. An FFP: PRBC transfusion ratio $>1: 1.5$ is associated with a lower risk of mortality after massive transfusion. J Trauma 2008; 65: 986 .

47. Rowell SE, Barbosa RR, Diggs BS, et al. Effect of high product ratio massive transfusion on mortality in blunt and penetrating trauma patients. J Trauma 2011; 71 (2 Suppl 3): S353-357. 10.1097/TA. 0b013e318227ef53.

48. Pati S, Matijevic N, Doursout MF, et al. Protective effects of fresh frozen plasma on vascular endothelial permeability, coagulation, and resuscitation after hemorrhagic shock are time dependent and dimin- ish between days 0 and 5 after thaw. J Trauma 2010; 69 (Suppl 1): S55-63. doi: 10.1097/TA.0b013e3181e453d4.

49. Watson JJ, Pati S, Schreiber MA. Plasma transfusion: history, current realities, and novel improvements. Shock 2016; 46: 468-479. doi: 10.1097/SHK.0000000000000663.

50. Sillesen M, Johansson PI, Rasmussen LS, et al. Fresh frozen plasma resuscitation attenuates platelet dysfunction compared with normal saline in a large animal modelof multisystem trauma. J Trauma Acute Care Surg 2014; 76: 998-1007. doi: 10.1097/TA.0000000000000193.

51. Cardenas JC, Cap AP, Swartz MD, et al. Plasma resuscitation promotes coagulation homeostasis following shock-induced hypercoagulability. Shock 2016; 45: 166-173. doi: 10.1097/SHK. 0000000000000504

52. Snyder CW, Weinberg JA, McGwin G Jr, et al. The relationship of blood product ratio to mortality: survival benefit or survival bias. J Trauma 2009; 66: 358-362. doi: 10.1097/TA.0b013e318196c3ac.

53. Holcomb JB, del Junco DJ, Fox EE, et al, PROMMTT Study Group. The prospective, observational, multicenter, major trauma transfusion (PROMMTT) study: comparative effectiveness of a time-varying treatment with competing risks. JAMA Surg 2013; 148: 127-136. doi: 10.1001/2013.jamasurg.387.

54. Oyeniyi BT, Fox EE, Scerbo M, et al. Trends in 1029 trauma deaths at a level 1 trauma center: Impact of a bleeding control bundle of care. Injury 2017; 48: 5-12. doi: 10.1016/j.injury.2016.10.037.

55. Holcomb JB, Tilley BC, Baraniuk S, et al, PROPPR Study Group. Transfusion of plasma, platelets, and red blood cells in a 1:1:1 vs a 1:1:2 ratio and mortality in patients with severe trauma: the PROPPR randomized clinical trial. JAMA 2015; 313: 471-482. doi: 10.1001/ jama.2015.12.

56. Fox EE, Holcomb JB, Wade CE, et al, PROPPR Study Group. Earlier endpoints are required for hemorrhagic shock trials among severely injured patients. Shock 2017; 47: 567-573. doi: 10.1097/ SHK.0000000000000788.

57. Sperry JL, Guyette FX, Brown JB, et al. Prehospital plasma during air medical transport in trauma patients at risk for hemorrhagic shock. N Engl J Med 2018; 379: 315-326. doi: 10.1056/NEJMoa1802345.

58. Moore HB, Moore EE, Chapman MP, et al. Plasma-first resuscitation to treat haemorrhagic shock during emergency ground transportation in an urban area: a randomised trial. Lancet 2018; 392: 283-391. doi: 10.1016/S0140-6736(18)31553-8.

59. Spinella PC, Pidcoke HF, Strandenes G, et al. Whole blood for hemostatic resuscitation of major bleeding. Transfusion 2016; 56(S2): S190-202. doi: 10.1111/trf.13491

60. Holcomb JB. Damage control resuscitation. J Trauma 2007; 62 (6 Suppl): S36-37. doi: 10.1097/TA.0b013e3180654134.

61. Spinella PC, Perkins JG, Grathwohl KW, et al. Warm fresh whole blood is independently associated with improved survival for patients with combat-related traumatic injuries. J Trauma 2009; 66 (4 Suppl): S69-76. doi: 10.1097/TA.0b013e31819d85fb.

62. Holcomb JB, Spinella PC. Optimal use of blood in trauma patients. Biologicals 2010; 38: 72-77. doi: 10.1016/j.biologicals.2009.10.007.

63. Golan M, Modan M, Lavee J, et al. Transfusion of fresh whole blood stored ( 4 degrees $\mathrm{C}$ ) for short period fails to improve platelet aggregation on extracelular matrix and clinical hemostasis after cardiopulmonary bypass. J Thorac Cardiovasc Surg 1990; 99: 354-360.

64. Cotton BA, Podbielski J, Camp E, et al.; Early Whole Blood Investigators. A randomized controlled pilot trial of modified whole blood versus componente therapy in severely injured patients requiring large volume transfusions. Ann Surg 2013; 258: 527-532 [discussion: 532533]. doi: 10.1097/SLA.0b013e3182a4ffa0.

65. Kauvar DS, Holcomb JB, Norris GC, et al. Fresh whole blood transfusion: a controversial military practice. J Trauma 2006; 61: 181-184. doi: 10.1097/01.ta.0000222671.84335.64

66. Repine TB, Perkins JG, Kauvar DS, et al. The use of fresh whole blood in massive transfusion. J Trauma 2006; 60 (6 Suppl): S59-69. doi: 10.1097/01.ta.0000219013.64168.b2

67. Bickell WH, Wall MJ Jr, Pepe PE, et al. Immediate versus delayed fluid resuscitation for hypotensive patients with penetrating torso injuries. N Engl J Med 1994; 331: 1105-1109. doi: 10.1056/NEJM1994102733 11701 .

68. Wall MJ Jr, Granchi TS, Liscum K, et al. Delayed versus immediate fluid resuscitation in patients with penetrating trauma: subgroup analysis. J Trauma 1995; 39: 173.

69. Schreiber MA, Meier EN, Tisherman SA, et al. A controlled resuscitation strategy is feasible and safe in hypotensive trauma patients: results of a prospective randomized pilot trial. J Trauma Acute Care Surg 2015; 78: 687. doi: 10.1097/TA.0000000000000600. 
70. Sondeen JL, Coppes VG, Holcomb JB. Blood pressure at which rebleeding occurs after resuscitation in swine with aortic injury. J Trauma 2003; 54 (5 Suppl): S110-117. doi: 10.1097/01.TA.0000047220.81795.3D.

71. Plotkin AJ, Wade CE, Jenkins DH, et al. A reduction in clot formation rate and strength assessed by thrombelastography is indicative of transfusion requirements in patients with penetrating injuries. J Trauma 2008; 64 (2 Suppl): S64-68. doi: 10.1097/TA.0b013e318160772d.

72. Spinella PC, Holcomb JB. Resuscitation and transfusion principles for traumatic hemorrhagic shock. Blood Rev 2009; 23: 231-240. doi: 10.1016/j.blre.2009.07.003

73. Cotton BA, Minei KM, Radwan ZA, et al. Admission rapid thrombelastography predicts development of pulmonary embolism in trauma patients. J Trauma Acute Care Surg 2012; 72: 1470-1475. doi: 10.1097/ TA.0b013e31824d56ad.

74. Holcomb JB, Minei KM, Scerbo ML, et al. Admission rapid thrombelastography can replace conventional coagulation tests in the emer gency department: experience with 1974 consecutive trauma patients. Ann Surg 2012; 256: 476-486. doi: 10.1097/SLA.0b013e3182658180.

75. Lockey DJ, Weaver AE, Davies GE. Practical translation of hemorrhage control techniques to the civilian trauma scene. Transfusion 2013; 53 (Suppl 1): 17S-22S. doi: 10.1111/trf.12031.

76. Gruen RL, Brohi K, Schreiber M, et al. Haemorrhage control in severely injured patients. Lancet 2012; 380: 1099-1108. doi: 10.1016/ S0140-6736(12)61224-0

77. Jacobs LM, Burns KJ, Langer G, Kiewiet de Jonge C. The Hartford Consensus: a national survey of the public regarding bleeding control. J Am Col Surg 2016; 222: 948-955. 10.1016/j.jamcollsurg.2016.02.013.

78. Fox N, Rajani RR, Bokhari F, et al.; Eastern Association for the Surgery of Trauma. Evaluation and management of penetrating lower extremity arterial trauma: an Eastern Association for the Surgery of Trauma practice management guideline. J Trauma Acute Care Surg 2012; 73 (5 Suppl 4): S315-320. doi: 10.1097/TA.0b013e31827018e4.

79. Sadek S, Lockey DJ, Lendrum RA, Perkins Z, Price J, Davies GE. Resuscitative endovascular balloon occlusion of the aorta (REBOA) in the pre-hospital setting: An additional resuscitation option for uncontrolled catastrophic haemorrhage. Resuscitation 2016; 107: 135 138. doi: 10.1016/j.resuscitation.2016.06.029.

80. Reva VA, Hörer TM, Makhnovskiy AI, Sokhranov MV, Samokhvalov IM DuBose JJ. Field and en route resuscitative endovascular occlusion of the aorta: A feasible military reality? J Trauma Acute Care Surg 2017; 83 (1 Suppl 1): S170-S176. doi: 10.1097/TA.0000000000001476.

81. Baraniuk S, Tilley BC, del Junco DJ, et al. Pragmatic Randomized Optimal Platelet and Plasma Ratios (PROPPR) trial: design, rationale and implementation. Injury 2014; 45: 1287-1295. doi: 10.1016/j.injury. 2014.06.001.

82. Brenner ML, Moore LJ, DuBose JJ, et al. A clinical series of resuscitative endovascular balloon occlusion of the aorta for hemorrhage control and resuscitation. J Trauma Acute Care Surg 2013; 75: 506 511. doi: 10.1097/TA.0b013e31829e5416.

83. Curry N, Foley C, Wong H, et al. Early fibrinogen concentrate therapy for major haemorrhage in trauma (E-FIT 1): results from a UK multi-centre, randomised, double blind, placebo-controlled pilot trial. Crit Care 2018; 22: 164. doi: 10.1186/s13054-018-2086-x.

84. Sorensen B, Tang M, Larsen OH, Laursen PN, Fenger-Eriksen C, Rea CJ. The role of fibrinogen: a new paradigm in the treatment of coagulopathic bleeding. Thromb Res 2011; 128 (Suppl 1): S13-16. doi: 10.1016/S0049-3848(12)70004-X.

85. CRASH-2 Trial Collaborators. Improving the evidence base for trauma care: progress in the international CRASH-2 trial. PLoS Clin Trials 2006; 1: e30. doi: https://doi.org/10.1371/journal.pctr.0010030.

86. Duchesne JC, Pereira BM, Fraga GP. Damage control resuscitation In: Trauma Surgery. Vol 1. Di Saverio S, Tugnoli, Catena F et al. (eds.). Springer 2014.

87. Sharpe D, Barneby E, Russell R. New approaches to the management of traumatic external hemorrhage. J Trauma 2011; 13: 47-55. doi: $10.1177 / 1460408610385739$

88. Bulger E, Snyder D, Schoelles K, et al. An evidence-based prehospital guideline for external hemorrhage control: American College of Surgeons Committee on Trauma. Prehosp Emerg Care 2014; 18: 163-173. doi: 10.3109/10903127.2014.896962.

89. Theodoridis CA, Kafka KE, Perez AM, et al. Evaluation and testing of junctional tourniquets by special operation forces personnel: a comparison of the combat ready clamp and the junctional emergency treatment tool. J Spec Oper Med 2016; 16: 44-50.

90. Granville-Chapman J, Jacobs N, Midwinter M. Pre-hospital haemostatic dressing: a systematic review. Injury 2011; 42: 447-459. doi: 10.1016/j.injury.2010.09.037. 